\title{
E-Polylysine Inhibits Shewanella putrefaciens with Membrane Disruption and Cell Damage
}

\author{
Weiqing LAN ${ }^{1,2,3,4,{ }^{\dagger}}$, Nannan ZHANG ${ }^{1}$, Shucheng $\operatorname{LIU}^{2,+}{ }^{+}$, Mengling CHEN ${ }^{1}$ and Jing XIE ${ }^{1,3,4, *}$ \\ 1 College of Food Science and Technology, Shanghai Ocean University, Shanghai 201306, China; \\ wqlan@shou.edu.cn (W.L.); 15836066261@163.com (N.Z.); chenml5211314@126.com (M.C.) \\ 2 College of Food Science \& Technology, Guangdong Provincial Key Laboratory of Aquatic Product Processing \\ and Safety, Guangdong Ocean University, Zhanjiang 524088, China; Lsc771017@163.com \\ 3 Shanghai Aquatic Products Processing and Storage Engineering Technology Research Center, \\ Shanghai 201306, China \\ 4 National Experimental Teaching Demonstration Center for Food Science and Engineering, \\ Shanghai Ocean University, Shanghai 201306, China \\ * Correspondence: jxie@shou.edu.cn; Tel.: +86-21-61900351; Fax: +86-21-61900365 \\ + These authors contributed equally to this work.
}

Academic Editors: Mingfu Wang and Yueliang Zhao

Received: 11 September 2019; Accepted: 14 October 2019; Published: 16 October 2019

Abstract: $\varepsilon$-Polylysine $(\varepsilon-\mathrm{PL})$ was studied for the growth inhibition of Shewanella putrefaciens (S. putrefaciens). The minimal inhibitory concentration (MIC) of $\varepsilon$-PL against S. putrefaciens was measured by the broth dilution method, while the membrane permeability and metabolism of S. putrefaciens were assessed after $\varepsilon$-PL treatment. Additionally, growth curves, the content of alkaline phosphatase (AKP), the electrical conductivity (EC), the UV absorbance and scanning electron microscope (SEM) data were used to study cellular morphology. The impact of $\varepsilon$-PL on cell metabolism was also investigated by different methods, such as enzyme activity (peroxidase $[\mathrm{POD}]$, catalase $[\mathrm{CAT}]$, succinodehydrogenase $[\mathrm{SDH}]$ and malic dehydrogenase $[\mathrm{MDH}]$ ) and cell metabolic activity. The results showed that the MIC of $\varepsilon$-PL against $S$. putrefaciens was $1.0 \mathrm{mg} / \mathrm{mL}$. When S. putrefaciens was treated with $\varepsilon$-PL, the growth of the bacteria was inhibited and the AKP content, electrical conductivity and UV absorbance were increased, which demonstrated that $\varepsilon-\mathrm{PL}$ could damage the cell structure. The enzyme activities of POD, CAT, SDH, and MDH in the bacterial solution with $\varepsilon$-PL were decreased compared to those in the ordinary bacterial solution. As the concentration of $\varepsilon$-PL was increased, the enzyme activity decreased further. The respiratory activity of $S$. putrefaciens was also inhibited by $\varepsilon$-PL. The results suggest that $\varepsilon$-PL acts on the cell membrane of S. putrefaciens, thereby increasing membrane permeability and inhibiting enzyme activity in relation to respiratory metabolism and cell metabolism. This leads to inhibition of cell growth, and eventually cell death.

Keywords: $\varepsilon$-polylysine ( $\varepsilon-\mathrm{PL})$; S. putrefaciens; membrane disruption; cell damage

\section{Introduction}

$\varepsilon$-Polylysine ( $\varepsilon-\mathrm{PL})$, a natural food preservative used commercially in Japan, has generally been recognized as safe [1]. Moreover, $\varepsilon$-PL has generally been recognized as a safe agent (GRAS No. 000135) by the Food and Drug Administration (FDA) and is commonly used in many foods, including soft drinks, cheese, egg-based dishes, salad dressings, fish, sauces and potato-based foods [1-4]. China has also approved it as a variety of food additive in April 2014. The main advantages of $\varepsilon$-PL is its water solubility, edibility and nontoxicity towards humans and the environment, as it can be degraded into lysine without any side effects for consumers [5]. Furthermore, $\varepsilon$-PL displays a broad spectrum of 
antimicrobial activity against most gram-negative and gram-positive bacteria, fungi and viruses [3]. Hence, $\varepsilon$-PL can be applied as a natural food additive in food products or as a disinfectant in dairy foods and their production equipment. A number of studies have demonstrated that $\varepsilon$-PL is effective in controlling foodborne bacteria, such as Escherichia coli, Staphylococcus aureus and Bacillus subtilis [6,7]. Although the antimicrobial activity of $\varepsilon$-PL and its application have been reported, its antimicrobial mechanism is vague and not thoroughly described.

S. putrefaciens has previously been shown to be one of the main spoilage organisms present in temperate fish species [8,9]. Nowadays, many studies have focused on antimicrobial techniques against S. putrefaciens. Schelegueda et al. [10] showed that the combined use of chitosan, nisin and sodium lactate inhibited the growth of $S$. putrefaciens by disrupting its outer membrane, affecting the ribosomes and DNA of the bacteria. Mu et al. [11] reported that $1 \%$ chitosan combined with $0.6 \%$ nisin had significant inhibitory effects on the growth and biofilm formation of S. putrefaciens and Shewanella algae in Pseudosciaena crocea. In addition, Fei et al. [12] showed that cinnamon oil combined with gamma radiation damaged the cell permeability and integrity of S. putrefaciens, while Zhang et al. [13] showed that Ginkgo biloba leaf extracts (GBLEs) damaged the morphology of S. putrefaciens.

Some researchers have shown that bacteriostatic agents could affect cell metabolism when they enter a bacterial cell after destroying its structure. Metabolic respiration produces cellular energy through the tricarboxylic acid cycle (TCA) and oxidative phosphorylation, which is used for cellular growth, multiplication, apoptosis and other cellular processes of living microorganisms [14]. The TCA cycle is not only the main method for gaining energy for the cell, but also the most common metabolic pathway for thorough oxidation of three main organic substances: sugar, fat, and protein. The respiratory system is one of the most common targets for antimicrobial agents. Additionally, defense enzymes play vital roles in host plant resistance against pathogen invasion, and reductions in disease severity in stressed plants have been attributed to changes in the activities of defense enzymes, such as peroxidase (POD) and catalase (CAT) [15].

Hence, the purpose of this research was to investigate the antibacterial mechanism of $\varepsilon$-PL against S. putrefaciens through (i) membrane leakage (alkaline phosphatase, electrical conductivity and ultraviolet absorption), (ii) mycelial morphology by scanning electron microscope (SEM) observation, (iii) enzyme activities (succinodehydrogenase (SDH), malic dehydrogenase (MDH), POD and CAT) in S. Putrefaciens, and (iv) cellular metabolism (viability) of the TCA pathway.

\section{Results and Discussion}

\subsection{Minimal Inhibitory Concentration (MIC)}

The MIC of $\varepsilon$-PL against $S$. putrefaciens was measured by conventional broth dilution assay, as depicted in Figure 1. $\mathrm{OD}_{600 \mathrm{~nm}}$ values decreased with an increase in $\varepsilon$-PL concentration, and the MIC of $\varepsilon$-PL against S. putrefaciens was found to be $1.0 \mathrm{mg} / \mathrm{mL}$. Moreover, the inhibitory effect of $\varepsilon$-PL against $S$. putrefaciens was positively correlated with the concentration of $\varepsilon$-PL. 


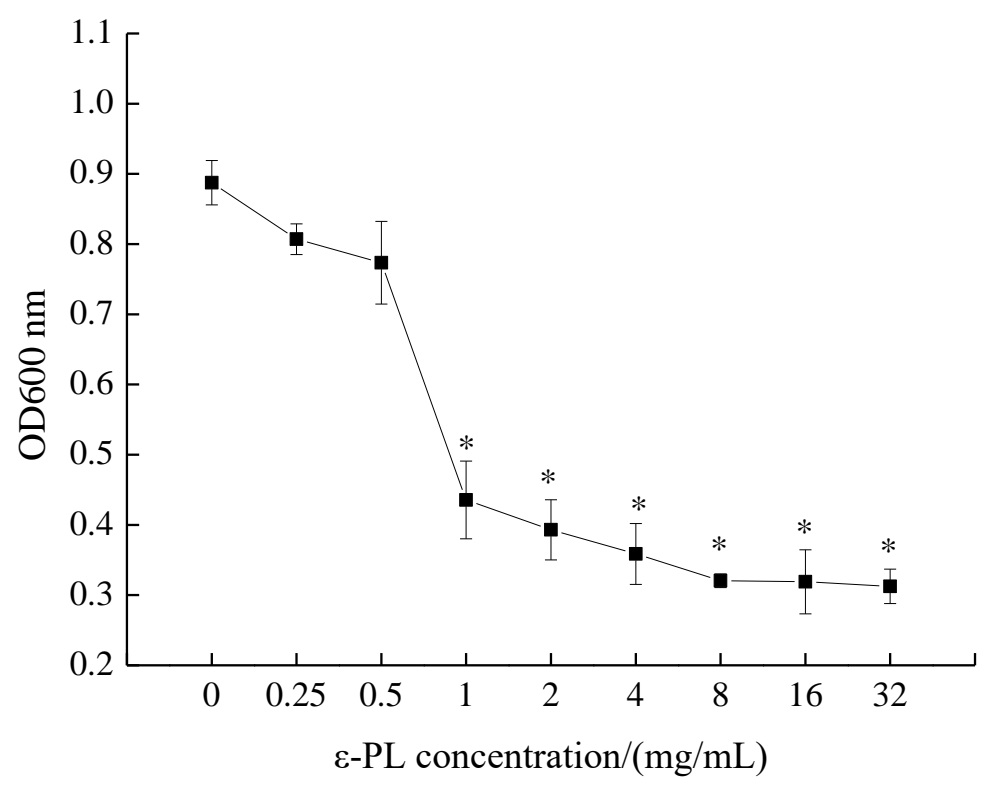

Figure 1. Minimal inhibitory concentration (MIC) of $\varepsilon$-polylysine ( $\varepsilon$-PL) against S. putrefaciens. Bars represent the standard error of the means. The superscript $\left(^{*}\right)$ indicates a result that is significantly different to the equivalent control point $(t$ test, $p<0.05)$.

\subsection{Growth Curve}

The time courses of bacteria growth in the presence of MIC and 2 MIC $\varepsilon$-PL were plotted so as to further confirm the antibacterial activity of $\varepsilon$-PL against $S$. putrefaciens. As shown in Figure 2, bacterial growth in the control group (CK) followed an S-shaped growth curve, with S. putrefaciens reaching the logarithmic phase after $2 \mathrm{~h}$ and the stationary phase after $13 \mathrm{~h}$. In addition, when $\varepsilon$-PL was added into the medium, the treated bacteria grew slower than the CK. Absorption values at $600 \mathrm{~nm}$ were lower than that of the control in almost each growth phase. These observed changes in the growth curves indicate antibacterial activity of $\varepsilon$-PL treatment, which suggests that $\varepsilon$-PL could delay the growth of S. putrefaciens.

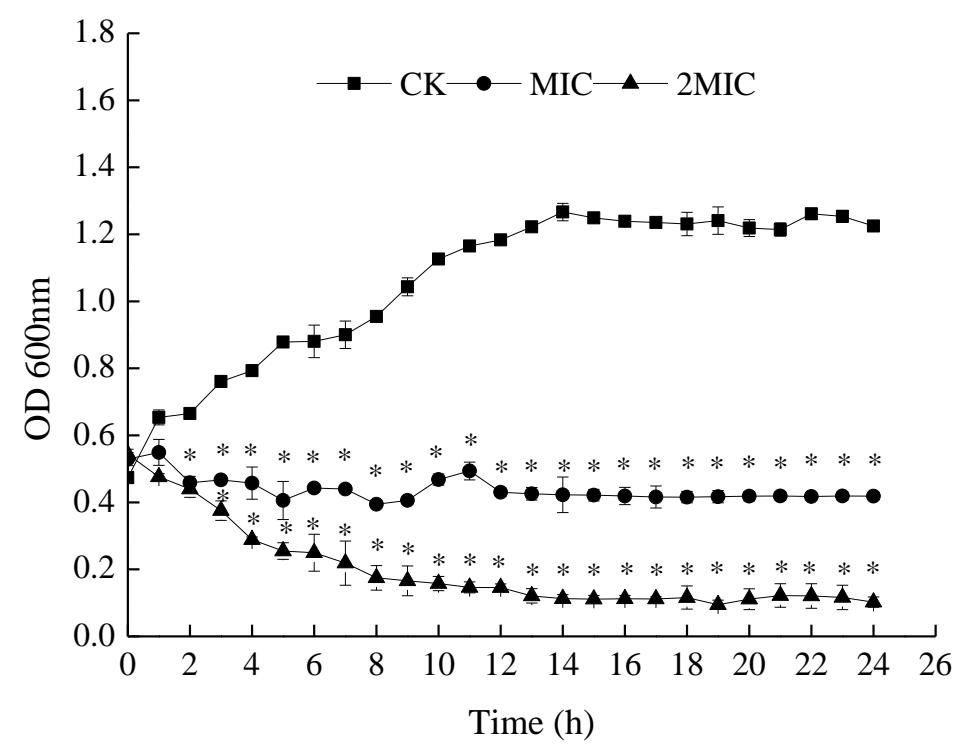

Figure 2. Effect of $\varepsilon$-PL on the growth curve of S. putrefaciens. Bars represent the standard error of the means. The superscript $\left(^{*}\right)$ indicates a result that is significantly different to the equivalent control point ( $t$ test, $p<0.05)$. 


\subsection{Characterizations of the Cell Membrane}

AKP is a kind of intracellular enzyme located between the cell wall and cell membrane; hence, its activity cannot be detected under normal conditions in the extracellular environment [16]. However, when the cell wall is damaged, AKP can leak out into the extracellular environment $[17,18]$. Therefore, the concentration of AKP in prepared cell suspensions may be used to reflect the integrity of bacterial cell walls.

As illustrated in Figure 3A, in the absence of $\varepsilon-\mathrm{PL}, \mathrm{AKP}$ activity was maintained at $3.20 \mathrm{U} / \mathrm{L}$. After treatment with MIC and 2 MIC $\varepsilon$-PL for $2 \mathrm{~h}$, the AKP activity increased from 3.32 to $4.54 \mathrm{U} / \mathrm{L}$ and from 3.32 to $5.91 \mathrm{U} / \mathrm{L}$, respectively. Obviously, the AKP activity from S. putrefaciens cells increased with an increase of $\varepsilon$-PL concentration (from MIC to $2 \mathrm{MIC}$ ). It has previously been reported that $\varepsilon$-PL induces cell wall damage, leading to AKP leakage from cells with the loss of cytoderm integrity [19]. Additionally, $\varepsilon$-PL can enter the inner membrane and lower the activity of AKP in S. putrefaciens, thus inhibiting bacterial growth. The decreased activity of AKP treated with $\varepsilon$-PL may prevent dephosphorylation progress, thereby inhibiting energy metabolism [15].

Electrical conductivity (EC) was examined to determine permeability changes in the cell membranes of the bacteria. As shown in Figure 3B, the EC values of the control were consistently lower than the $\varepsilon$-PL treated groups. With respect to the two $\varepsilon$-PL treated groups, the EC values of S. putrefaciens were larger for 2 MIC group. This increase in the EC of the treated bacterial suspension suggests the permeability of the cell membrane improved with $\varepsilon$-PL treatment, which may be caused by interactions between $\varepsilon$-PL and the cell membrane, thus leading to intracellular leakage of ions like $\mathrm{Na}^{+}$and $\mathrm{K}^{+}[16]$.

The release of cell constituents corresponds to the integrity of the cell membrane. Small ions such as potassium and phosphate tend to flow out first, followed by macromolecular substances such as nucleotides [20]. Thus, these are good indicators for evaluating the integrity of the cell membrane [21]. The detection of absorbance at $260 \mathrm{~nm}$ could be used to estimate the amount of nucleotide leakage from the cytoplasm. The absorption of bacterial supernatant is shown in Figure 3C. Evidently, the absorbance at $260 \mathrm{~nm}$ increases immediately after $2 \mathrm{~h}$ of treatment by $\varepsilon$-PL, which indicates leakage of nucleotides from the $S$. putrefaciens cells into the extracellular environment. It may be speculated that damage to the outer membrane of $S$. putrefaciens is the main cause of release of intracellular components into the supernatant. These results indicate that $\varepsilon$-PL treatment results in damage to $S$. putrefaciens cells. The cell membrane is an important structural component of bacteria and a major site of action of various antibacterial agents [22]. When the cell membrane is damaged, the contents within the cell, such as some large molecules (nucleic acids) and ions $\left(\mathrm{Na}^{+}, \mathrm{K}^{+}\right.$and phosphate ions), will leak out. Accordingly, leakage of intracellular material is an important indicator of the integrity of the cell membrane.

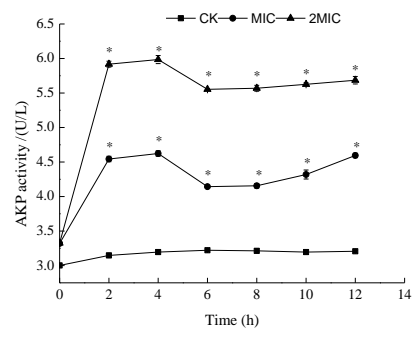

(A)

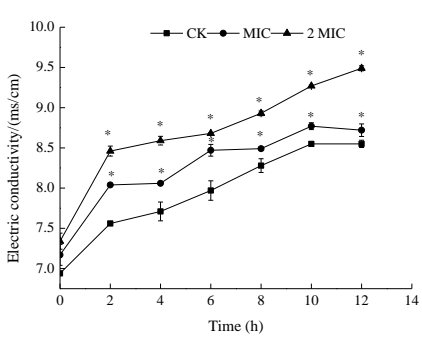

(B)

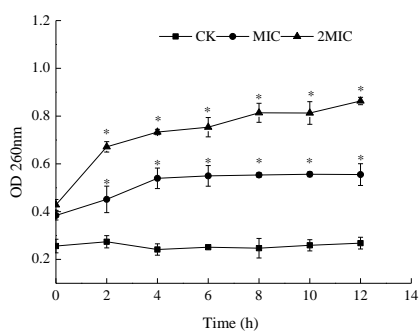

(C)

Figure 3. Effects of $\varepsilon$-PL on AKP (A), Electrical conductivity (B) and OD $260 \mathrm{~nm}$ (C) of S. putrefaciens. Bars represent the standard error of the means. The superscript $\left(^{*}\right)$ indicates a result that is significantly different to the equivalent control point ( $t$ test, $p<0.05$ ). 


\subsection{Scanning Electron Microscope (SEM)}

Morphology changes in the S. putrefaciens cells were evaluated by SEM analysis. Figure 4 shows SEM photomicrographs of $S$. putrefaciens cells treated with $\varepsilon$-PL.

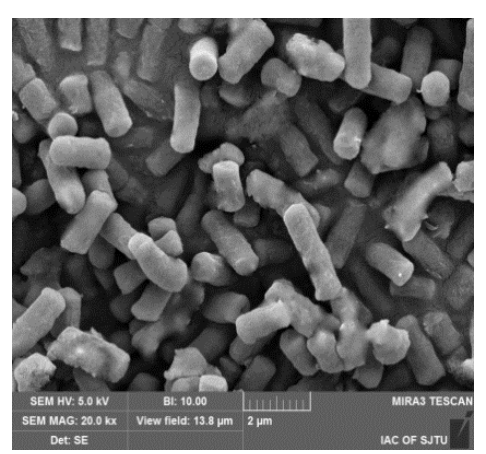

CK $(\times 20,000)$

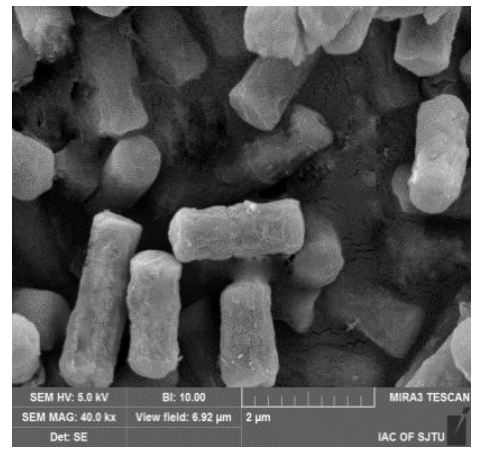

CK $(\times 40,000)$

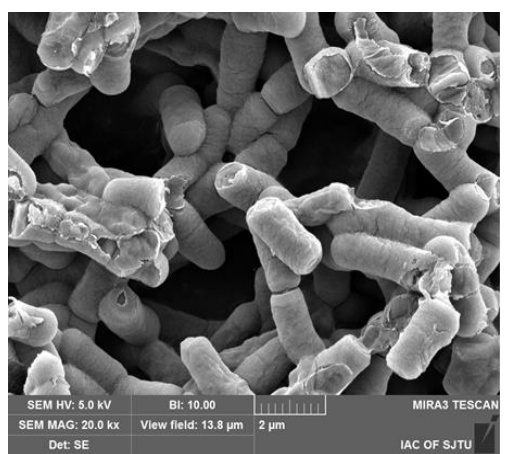

$\operatorname{MIC}(\times 20,000)$

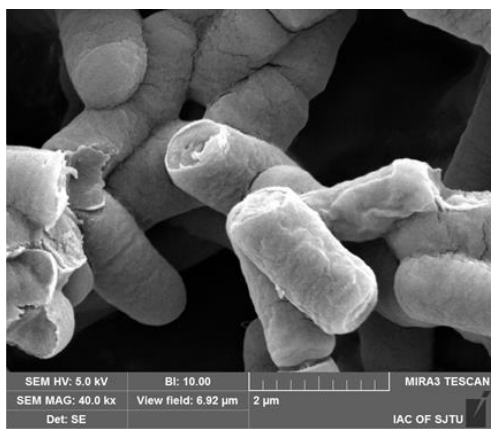

$\operatorname{MIC}(\times 40,000)$

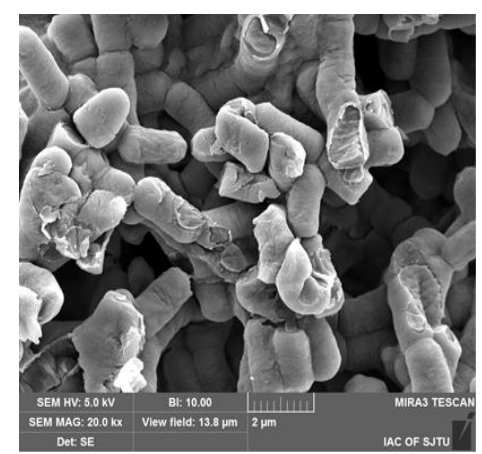

$2 \operatorname{MIC}(\times 20,000)$

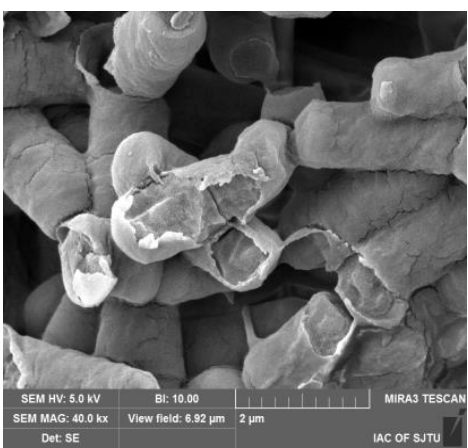

$2 \operatorname{MIC}(\times 40,000)$

Figure 4. Scanning electron microscope (SEM) images of S. putrefaciens treated with sterile water (CK), $1 \mathrm{mg} / \mathrm{mL} \varepsilon$-PL (1 MIC) and $2 \mathrm{mg} / \mathrm{mL} \varepsilon$-PL (2 MIC).

As seen in Figure 4, the bacterial cells of S. putrefaciens without $\varepsilon$-PL had a regular, short-bar-shaped morphology, with a smooth and intact cell surface. Furthermore, the surface appeared full and glossy. In contrast to the control, S. putrefaciens cells treated with $\varepsilon$-PL (MIC and 2 MIC) were deformed, shriveled, pitted and swelled, with parts of the cell appearing broken and shrunk to a smaller size.

The results obtained by the SEM (Figure 5) testify to membrane damage and leakage of bacterial contents following treatment with $\varepsilon$-PL. Lin et al. [16] also reported that $\varepsilon$-PL could act on the membrane of $L$. monocytogenes, affecting the integrity of the membrane and inducing the loss of intracellular materials, enzymes and soluble proteins.

\subsection{Effect of $\varepsilon-P L$ on Respiratory Metabolism}

\subsubsection{Measurement of ATPase Activities}

ATP is produced in both the cell wall and cell membrane of bacteria via the glycolysis process. Bacterial membranes have multiple enzymes that can contribute to ATP generation and metabolism. ATPase is one of the most important enzymes for this mechanism [23]. ATPase catalyzes ATP to ADP, thus providing energy for cells. Since these enzymes provide cells with cofactors and energy, a decrease in their activity presumably impedes carbohydrate metabolism, which in turn retards cell growth or even leads to cell death [24]. This part of the study was performed to investigate the inhibition mechanism of $\varepsilon$-PL on the activity of ATPase. Figure 5 shows that the ATPase activity of the control sample was stable. On the contrary, the activity of ATPase exposed to $\varepsilon$-PL decreased remarkably. This decrement in the ATPase level of S. putrefaciens treated with $\varepsilon$-PL indicates that the $\varepsilon$-PL disrupted 
the cell membrane, inhibiting intracellular ATPase activity. This also led to the loss of the balance of external ATPase activity.

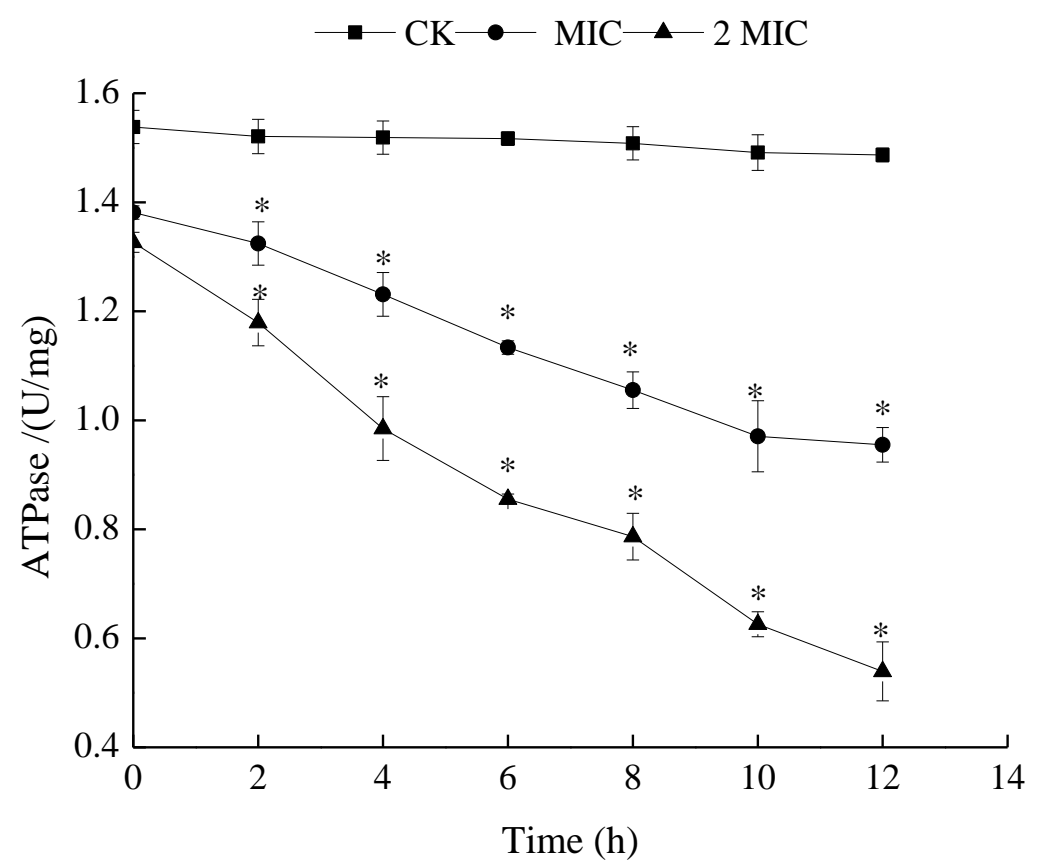

Figure 5. Effects of $\varepsilon$-PL against on ATPase activity of S. putrefaciens. Bars represent the standard error of the means. The superscript $\left({ }^{*}\right)$ indicates a result that is significantly different to the equivalent control point $(t$ test, $p<0.05)$.

Lower ATPase activity may cause an outflow of ATP content from the bacteria, impeding its respiratory metabolism. Lin et al. [16] also found that $\varepsilon$-PL inhibited the respiration of L. monocytogenes by determining a change in its ATPase activity.

\subsubsection{Measurement of Peroxidase (POD) and Catalase (CAT) Activities}

POD, a kind of oxidoreductase, and CAT, a kind of antioxidant, exist in all microorganisms. These enzymes correlate with microbial activity and respiration, maintaining the balance of active oxygen by converting $\mathrm{H}_{2} \mathrm{O}_{2}$ to $\mathrm{H}_{2} \mathrm{O}$ and $\mathrm{O}_{2}{ }^{-}$[15]. They both exist widely in aerobic organisms and are an important part of the protective enzyme systems in a cell. POD and CAT can not only remove reactive oxygen radicals and prevent the destruction of a cell by physiochemical changes, they can also reduce the deposition of reactive oxygen in cells so as to ensure the integrity of the cell membrane and other structures. If their activity is inhibited, the operation of the whole enzyme system is greatly affected, and the protective function of the enzyme system is reduced or even lost. In the case of bacteria, a decrease of POD activity causes damage to the bacterial membrane system, which reduces the ability of the bacteria to resist external influences and ultimately affects the growth and metabolism of the microorganism.

As shown in Figure 6, the POD activity of S. putrefaciens treated with $\varepsilon$-PL decreased with an increase in processing time, while the normal solution remained relatively unchanged. Furthermore, the POD activity decreased obviously with the increase of $\varepsilon-P L$ concentration. The tendencies of POD were similar to those of CAT. In summary, $\varepsilon$-PL inhibited CAT and POD activities of S. putrefaciens. Such results can be justified by the fact that POD and Superoxide Dismutase (SOD) activities may be generally considered as important in the resistance of $S$. putrefaciens.

POD and CAT are important protective enzymes in biological organisms and can scavenge oxidized free radicals in the body [25]. The lower the activity of POD and CAT, the weaker the cell's ability to eliminate free radicals. These results show that $\varepsilon$-PL may prevent the growth of S. putrefaciens 
by hindering the transfer of information and energy, or by inhibiting the self-protection ability of the bacteria. Since these enzymes provide cells with cofactors and energy, decreases in their activities presumably impedes carbohydrate metabolism, which in turn retards cell growth or even leads to cell death.

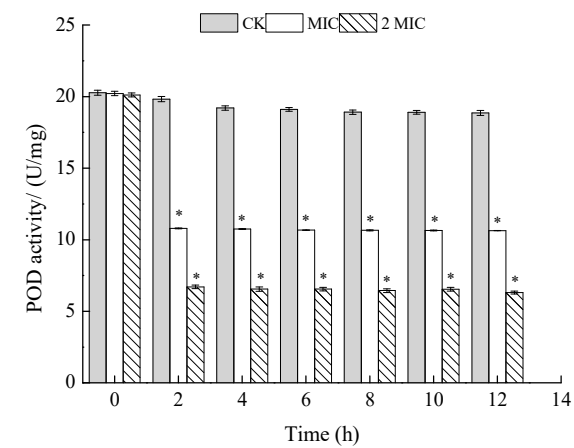

(A)

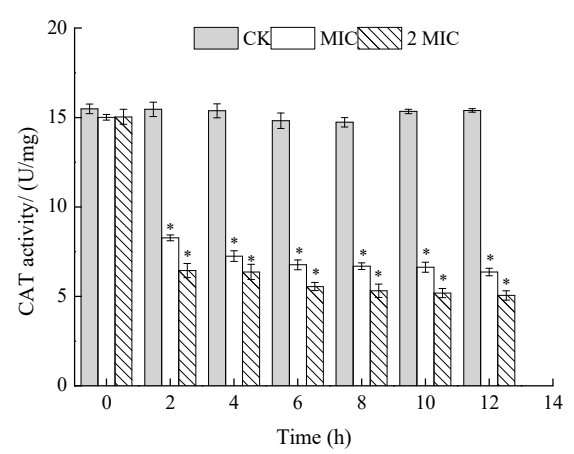

(B)

Figure 6. Effects of $\varepsilon$-PL on peroxidase (POD) (A) and catalase (CAT) (B) activity of S. putrefaciens. Bars represent the standard error of the means. The superscript $\left.{ }^{*}\right)$ indicates a result that is significantly different to the equivalent control point $(t$ test, $p<0.05)$.

\subsubsection{Measurement of Succinodehydrogenase (SDH) and Malicdehydrogenase (MDH) Activities}

$\mathrm{SDH}$ is located in the inner mitochondrial membrane. This enzyme catalyzes succinic acid conversion to fumaric acid and simultaneously produces $\mathrm{FADH}_{2}$. SDH links oxidative phosphorylation to respiration metabolism, and thus is a representative enzyme in the mitochondria [24]. SDH activity in the treated cells decreased with increasing time, while it remained stable in the untreated cells (Figure 7). Compared with the control samples, the SDH activity of S. putrefaciens treated with $\varepsilon-\mathrm{PL}$ decreased. $\mathrm{MDH}$ is a representative enzyme in the tricarboxylic acid (TCA) cycle, which catalyzes L-malic acid to oxalacetic acid and simultaneously produces NADH [24]. Changes in MDH activity followed a similar pattern to that of SDH (Figure 7). After treatment with MIC and 2 MIC of $\varepsilon$-PL, the MDH activity of $S$. putrefaciens decreased. As expected, $\varepsilon$-PL treatment of $S$. putrefaciens resulted in significantly decreased activities of SDH and MDH in the bacteria, with the activity of the enzymes being inversely proportional to $\varepsilon$-PL concentration. These results were in agreement with Yang et al. [26], who observed lower SDH and MDH activity in Penicillium italicum.

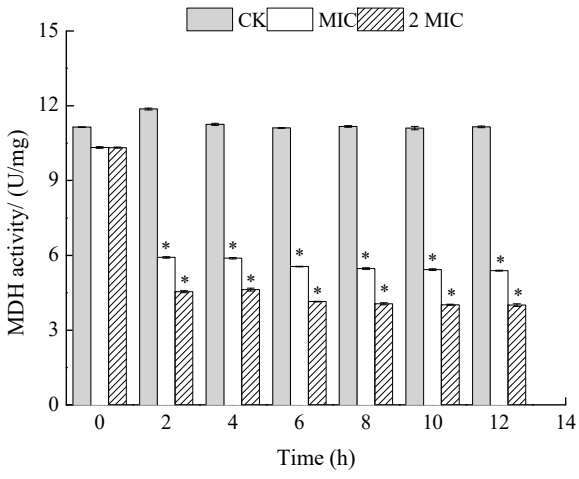

(A)

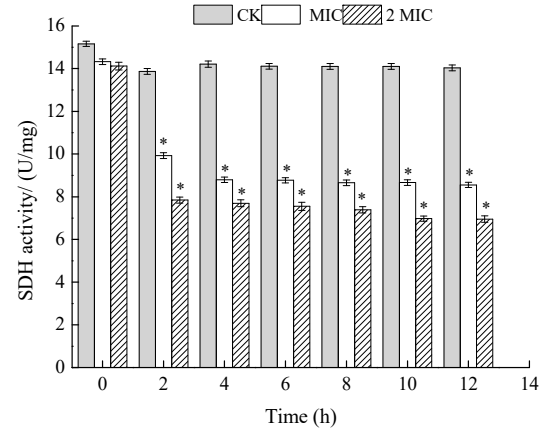

(B)

Figure 7. Effects of $\varepsilon$-PL on malicdehydrogenase (MDH) (A) and succinodehydrogenase (SDH) (B) activity of $S$. putrefaciens. Bars represent the standard error of the means. The superscript $\left(^{*}\right)$ indicates a result that is significantly different to the equivalent control point $(t$ test, $p<0.05)$. 
All kinds of metabolism in living organisms are carried out under the catalysis of enzymes. The TCA cycle is not only the main way to gain energy for the cell, but it is also the common metabolic pathway for thorough oxidation of three main organic substances: sugar, lipids, and protein. Among all the enzymes in the TCA cycle, it seems that SDH links oxidative phosphorylation to respiration metabolism, and thus is a representative enzyme in the mitochondria. MDH widely exists in the mitochondria and bacterial cell membrane, and there are differences in its type in different organisms. $\mathrm{MDH}$ is closely related to the heredity, species category, growth and reproduction of cells or bacteria, and is an important enzyme in organisms [26]. In this study, $\varepsilon$-PL inhibited the activities of SDH and $\mathrm{MDH}$, indicating retarded respiration, impeded cell viability, and even cell death. Studies have shown that in vivo Iodonitrotetrazolium chloride (INT) reduction may be used in marine bacteria to estimate respiration rate [27]. Through our research, the production rate of formazan was used to represent the metabolic activity of $S$. putrefaciens in the TCA cycle. With increasing concentration of $\varepsilon$-PL, the production rate of formazan gradually decreased, and the TCA of S. putrefaciens was blocked. In summary, these results suggest that $\varepsilon$-PL depressed the metabolic activities of S. putrefaciens by targeting key enzymes in the tricarboxylic acid (TCA) cycle.

\subsubsection{Effect of $\varepsilon$-PL on Cellular Metabolism (Viability)}

The principle of determining the metabolic activity of cells by INT is that living cells can generate $\mathrm{H}^{+}$via dehydrogenase activity during the TCA cycle. $\mathrm{H}^{+}$can restore INT to a stable red formazan. The metabolic activity of bacteria is judged by the production rate of formazan. A reduction of $\mathrm{OD}_{630 \mathrm{~nm}}$ means a reduction in the production rate of formazan and thus weakened metabolism. In this work, with an increase in the concentration of $\varepsilon-\mathrm{PL}$, the $\mathrm{OD}_{630 \mathrm{~nm}}$ was found to decrease significantly, with its inhibitory effect becoming stronger (Figure 8). Thus, the cellular metabolism (viability) of S. putrefaciens was inhibited by $\varepsilon$-PL.

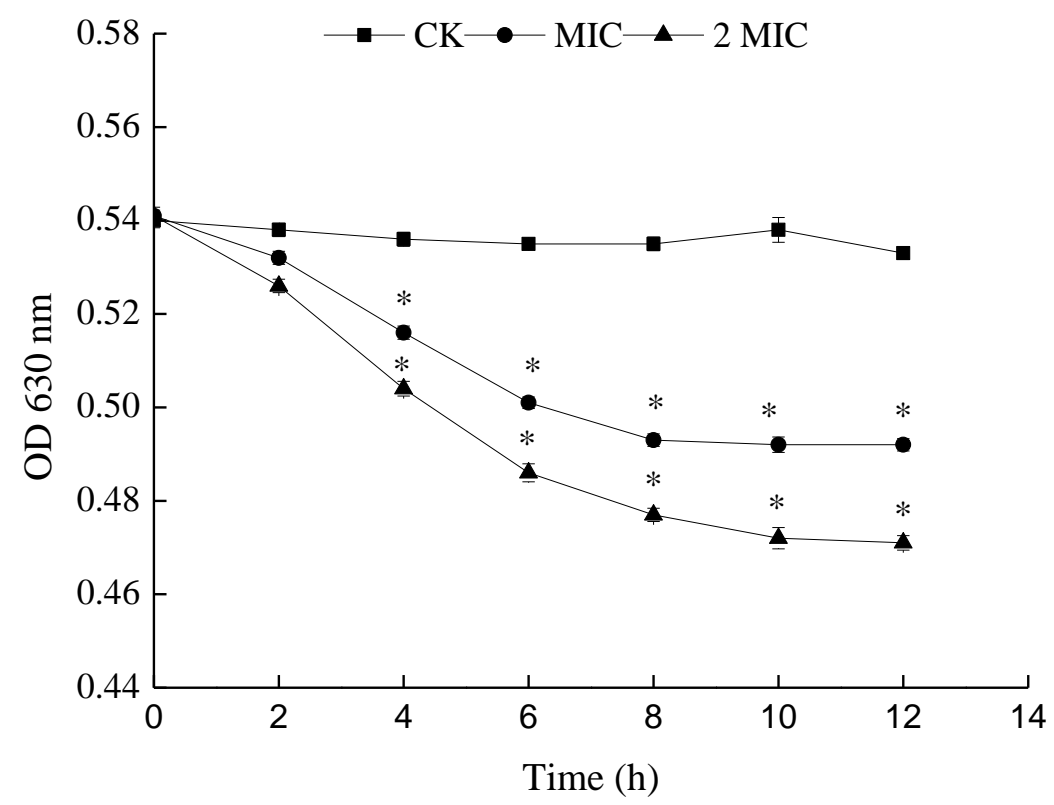

Figure 8. Effects of $\varepsilon$-PL on cell metabolism of S. putrefaciens. Bars represent the standard error of the means. The superscript $\left({ }^{*}\right)$ indicates a result that is significantly different to the equivalent control point ( $t$ test, $p<0.05)$. 


\section{Materials and Methods}

\subsection{Bacterial Culture}

S. putrefaciens were separated and purified from a large yellow croaker (Pseudosciaena crocea), identified and preserved by Shanghai Engineering Research Center of Aquatic Product Processing and Preservation.

\subsection{Determination of Minimal Inhibitory Concentrations (MICs)}

MIC was measured by referring to the conventional broth dilution method of Li et al. [6] with some modifications. S. putrefaciens were incubated at $37^{\circ} \mathrm{C}$ for $8-10 \mathrm{~h}$ to approximately $10^{6}-10^{7} \mathrm{CFU} / \mathrm{mL}$ in Tryptic Soy Broth (TSB) medium. $\varepsilon$-PLs of serial dilutions, previously dissolved in sterile distilled water, were prepared to final concentrations of $0,0.25,0.5,1,2,4,8,16$ and $32 \mathrm{mg} / \mathrm{mL}$ of TSB medium. After $18-24 \mathrm{~h}$ shake incubation $\left(150 \mathrm{rpm}\right.$ at $\left.37^{\circ} \mathrm{C}\right)$, MIC was determined as the lowest concentration of $\varepsilon$-PL which visibly inhibited microorganism growth, which was confirmed by measuring the $\mathrm{OD}_{600 \mathrm{~nm}}$ of all treatments with a spectrophotometer (V-1100, Meipuda Instrument Co. Ltd., Shanghai, China). The sample without $\varepsilon$-PL was set as the control.

\subsection{Bacterial Growth Curve}

The inhibition effect of $\varepsilon$-PL on the growth of S. putrefaciens was evaluated. In brief, the logarithmic phase-tested bacteria were harvested and adjusted to $1.0 \times 10^{7} \mathrm{CFU} / \mathrm{mL}$ with TSB broth. One $\mathrm{mL}$ of the bacterial suspension was inoculated into the flasks containing $100 \mathrm{~mL}$ fresh sterile TSB broth. $\varepsilon$-PL was added to the culture to keep a final concentration of MIC and 2 MIC. The tested bacteria culture without $\varepsilon$-PL was used as the control. All cultures were incubated on an orbital shaker (150 rpm at $37^{\circ} \mathrm{C}$ ). The growth rates and bacterial concentrations were monitored every hour by measuring the $\mathrm{OD}_{600 \mathrm{~nm}}$ values using a Microplate Reader (Bioscreen Co., Helsinki, Finland).

\subsection{Effects of $\varepsilon$-PL on the Cell Wall and Membrane Permeability of S. putrefaciens}

S. putrefaciens were cultured to the logarithmic phase before treatment with MIC and 2 MIC $\varepsilon$-PL. Samples without $\varepsilon$-PL were set as the control samples. All cultures were incubated on an orbital shaker $\left(150 \mathrm{rpm}\right.$ at $\left.37^{\circ} \mathrm{C}\right)$. Aliquots of the samples were drawn at regular intervals $(2 \mathrm{~h})$ and centrifuged (3500 r/min, $10 \mathrm{~min})$.

\subsubsection{Alkaline Phosphate (AKP) Activity}

The effects of $\varepsilon$-PL on AKP were studied using the AKP assay kit, purchased from the Nanjing Jiancheng Bioengineering Institute (Jiangsu, China). The AKP levels were measured using the kits in line with the manufacturer's instructions. Changes in absorbance at $520 \mathrm{~nm}$ were measured to represent the activity of AKP.

\subsubsection{Electrical Conductivity (EC) Measurement}

Changes in the EC of the surface of the cell membranes were recorded by a portable multi-parameter analyzer (DZS-718, Shanghai Precision Science Instrument Co., Ltd., Shanghai, China).

\subsubsection{Determination of Nucleic Acid Leakage $\left(\mathrm{OD}_{260 \mathrm{~nm}}\right)$}

The measurement of the leakage of nucleic acid was carried out using the method reported by Wang et al. [28] with some modifications. Firstly, the bacterial suspension was washed three times with distilled water by centrifugation (6000 rpm for $10 \mathrm{~min}$ at $4{ }^{\circ} \mathrm{C}$ ). The suspensions were then prepared to contain $10^{7} \mathrm{CFU} / \mathrm{mL}$ in $0.9 \%$ sterile $\mathrm{NaCl}$. Aliquots of the samples were drawn at regular intervals $(1 \mathrm{~h})$ and centrifuged. The absorbance of $260 \mathrm{~nm}$ UV-absorbing materials in the suspension was then measured by an ultraviolet-visible light detector (Unico Instrument Co. LTD, Shanghai, China). 


\subsection{Scanning Electron Microscope (SEM) Observations}

The prepared $1 \%$ bacterial solution of $S$. putrefaciens was inoculated into the $\varepsilon$-PL solution. The inoculations were incubated at $37^{\circ} \mathrm{C}$ with shaking $(150 \mathrm{rpm})$ for $12 \mathrm{~h}$. The bacterial cells were collected by centrifugation at $8000 \mathrm{r} / \mathrm{min}$ for $5 \mathrm{~min}$ at $4{ }^{\circ} \mathrm{C}$. The bacteria precipitations were fixed in $2.5 \%$ glutaraldehyde solution at $4{ }^{\circ} \mathrm{C}$ for $10 \mathrm{~h}$. The fixed bacteria cells were washed three times with phosphate buffer solution (PBS), followed by serial dehydration with $30 \%, 50 \%, 70 \%, 90 \%$ and $100 \%$ ethanol solutions at $1 \mathrm{~min}$ intervals. After $12 \mathrm{~h}$ of freeze-drying, the cells were covered through cathodic spraying, after which SEM observations were performed.

\subsection{Effect of $\varepsilon$-PL on Respiratory Metabolism}

\subsubsection{Measurement of Adenosine Triphosphatase (ATPase)}

The effects of $\varepsilon$-PL on ATPase were studied using an ATPase assay kit, purchased from the Nanjing Jiancheng Bioengineering Institute (Jiangsu, China). The ATPase levels were measured using the kits in line with the manufacturer's instructions. Changes in absorbance at $636 \mathrm{~nm}$ were taken to function as the ATPase level.

\subsubsection{Measurement of Peroxidase (POD) and Catalase (CAT) Activities}

The POD and CAT activities of S. putrefaciens cells with $\varepsilon$-PL at various concentrations $(0$, MIC and 2 MIC) were determined using commercially available spectrophotometry kits (Nanjing Jiancheng Bioengineering Institute, Jiangsu, China) following the manufacturer's instructions. POD and SDH activities were determined at 420 and $405 \mathrm{~nm}$, respectively.

\subsubsection{Measurement of Succinodehydrogenase (SDH) and Malicdehydrogenase (MDH) Activities}

The SDH and MDH activities of S. putrefaciens with $\varepsilon$-PL at various concentrations (0, MIC and 2 MIC) were determined using commercially available spectrophotometry kits (Jiancheng Bioengineering Institute, Jiangsu, China) following manufacturer's instructions. MDH activities were estimated at $340 \mathrm{~nm}$ in terms of the redox reaction and SDH activities were determined at $600 \mathrm{~nm}$.

\subsection{Effect of $\varepsilon$-PL on Cellular Metabolism (Viability)}

The inhibition effect of $\varepsilon$-PL on cellular metabolism (viability) of S. putrefaciens was evaluated according to [29] with slight modifications. Bacteria in the logarithmic phase were harvested by centrifugation at $5000 \mathrm{r} / \mathrm{min}$ for $10 \mathrm{~min}$. The concentration of S. putrefaciens was adjusted to $10^{6} \mathrm{CFU} / \mathrm{mL}$ by washing and resuspending with saline. In order to achieve the final concentrations of 0,1 and $2 \mathrm{MIC}$, different volumes of $\varepsilon$-PL were added to a bacterial suspension. After incubation at $37^{\circ} \mathrm{C}$ for $1 \mathrm{~h}$, the mixture was centrifuged at $10,000 \mathrm{r} / \mathrm{min}$ for $10 \mathrm{~min}$ and the thallus was resuspended with $0.9 \%$ saline. Iodonitrotetrazolium chloride (INT, $1 \mathrm{mmol} / \mathrm{L}$ final concentration) was added to the solution, followed by incubation conducted at $37^{\circ} \mathrm{C}$ for $30 \mathrm{~min}$. The maximum absorbance of formazan was measured at $630 \mathrm{~nm}$ as an estimate of the cellular metabolism (viability).

\subsection{Statistical Analysis}

The experiment followed a completely randomized design $(n=3)$. Analyses were performed by SPSS 16.0 software package and curves were drawn by Origin 8.6. One-way analysis of variance (ANOVA) and Student's t-tests were used to elucidate significant differences at a significance level of $p<0.05$.

\section{Conclusions}

From our findings, we suggest $\varepsilon$-PL may inhibit S. putrefaciens through the following aspects. The Schematic representation of the possible inhibitory mechanisms of $\varepsilon$-PL against $S$. putrefaciens was 
as shown in Figure 9. Firstly, $\varepsilon$-PL may affect the cell structure of S. putrefaciens and cause irreversible damage to the cell membrane. Evidence of leakage of some large molecules (nucleic acids), ions ( $\mathrm{Na}^{+}$ and $\mathrm{K}^{+}$) and intracellular enzymes (AKP and ATPase) supports this suggestion. Besides, $\varepsilon$-PL appears to be capable of damaging bacterial morphology. Secondly, our results indicate that $\varepsilon$-PL inhibits the physiological activity of $S$. putrefaciens via its effect on defense enzymes (POD and CAT) of the respiratory system and key enzymes (SDH and $\mathrm{MDH})$ of the TCA cycle. $\varepsilon$-PL appears to decrease the TCA cycle and biosynthesis of $S$. putrefaciens, which can lead to bacterial decomposition and eventual death. Further work is also needed to test $\varepsilon$-PL against S. putrefaciens by Embden-Meyerhof-Parnas (EMP) and Hexose Monophosphate Pathway (HMP).

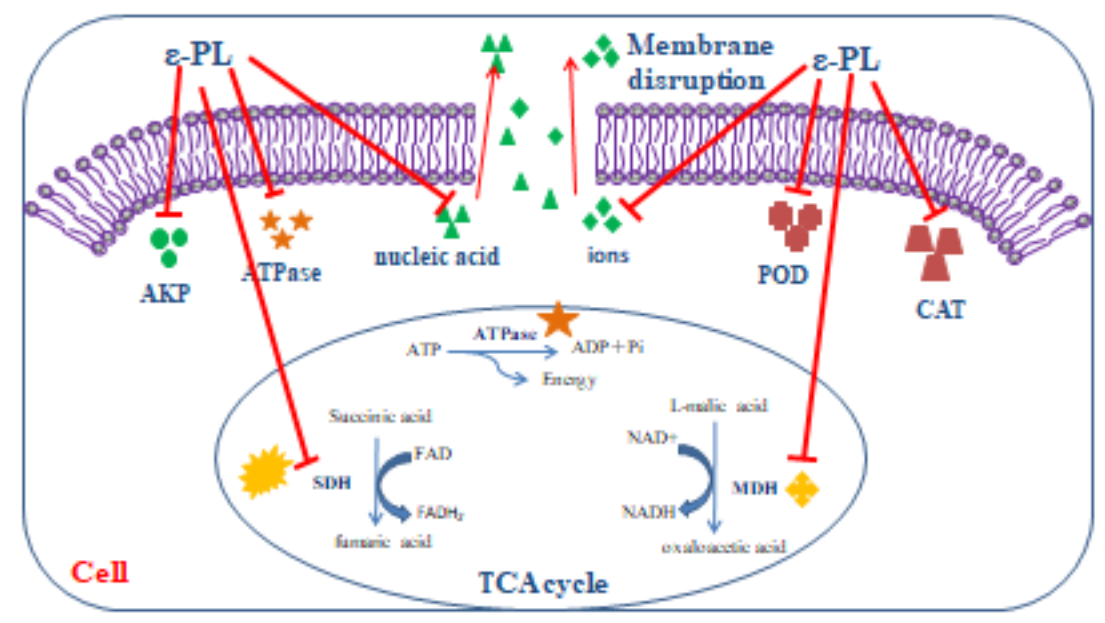

Figure 9. Schematic representation of the possible inhibitory mechanisms of $\varepsilon$-PL against S. putrefaciens.

Author Contributions: Writing_review and editing, W.L.; writing—original draft preparation, N.Z.; funding acquisition, S.L.; data curation, M.C.; project administration, J.X.

Funding: The study was financially supported by National Natural Science Foundation of China (grant number: 31972142), China Agriculture Research System (CARS-47-G26), Guangdong Provincial Key Laboratory of Aquatic Product Processing and Safety (GDPKLAPPS1802), Ability promotion project of Shanghai Municipal Science and Technology Commission Engineering Center (19DZ2284000).

Conflicts of Interest: Authors declare no conflict of interest.

\section{References}

1. Morten, H.; Tina, M.; Vad, B.S.; Marcel, S.; Otzen, D.E.; Meyer, R.L. The antimicrobial mechanism of action of epsilon-poly-l-lysine. Appl. Env. Microbiol. 2014, 80, 7758-7770.

2. Miya, S.; Takahashi, H.; Hashimoto, M.; Nakazawa, M.; Kuda, T.; Koiso, H.; Kimura, B. Development of a controlling method for Escherichia coli O157:H7 and Salmonella spp. in fresh market beef by using polylysine and modified atmosphere packaging. Food Control 2014, 37, 62-67. [CrossRef]

3. Shih, I.-L.; Shen, M.-H.; Van, Y.-T. Microbial synthesis of poly( $\varepsilon$-lysine) and its various applications. Bioresour. Technol. 2006, 97, 1148-1159. [CrossRef] [PubMed]

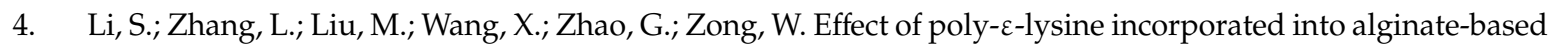
edible coatings on microbial and physicochemical properties of fresh-cut kiwifruit. Postharvest Biol. Technol. 2017, 134, 114-121. [CrossRef]

5. Shukla, S.C.; Singh, A.; Pandey, A.K.; Mishra, A. Review on production and medical applications of $\varepsilon$-polylysine. Biochem. Eng. J. 2012, 65, 70-81. [CrossRef]

6. Li, Y.-Q.; Han, Q.; Feng, J.-L.; Tian, W.-L.; Mo, H.-Z. Antibacterial characteristics and mechanisms of $\varepsilon$-poly-lysine against Escherichia coli and Staphylococcus aureus. Food Control 2014, 43, 22-27. [CrossRef]

7. Liu, H.; Pei, H.; Han, Z.; Feng, G.; Li, D. The antimicrobial effects and synergistic antibacterial mechanism of the combination of $\varepsilon$-Polylysine and nisin against Bacillus subtilis. Food Control 2015, 47, 444-450. [CrossRef] 
8. Qingqing, G.; Linglin, F.; Yanbo, W.; Junda, L. Identification and Characterization of Extracellular Cyclic Dipeptides As Quorum-Sensing Signal Molecules from Shewanella baltica, the Specific Spoilage Organism of Pseudosciaena crocea during $4{ }^{\circ} \mathrm{C}$ Storage. J. Agric. Food Chem. 2013, 61, 11645-11652.

9. Zhu, J.; Zhao, A.; Feng, L.; Gao, H. Quorum sensing signals affect spoilage of refrigerated large yellow croaker (Pseudosciaena crocea) by Shewanella baltica. Int. J. Food Microbiol. 2016, 217, 146-155. [CrossRef]

10. Schelegueda, L.I.; Zalazar, A.L.; Gliemmo, M.F.; Campos, C.A. Inhibitory effect and cell damage on bacterial flora of fish caused by chitosan, nisin and sodium lactate. Int. J. Biol. Macromol. 2016, 83, 396-402. [CrossRef]

11. Mu, H.; Guo, Q.Y.; Wei, S.; Li, B.G.; Zhang, G.W. Inhibitory effects of chitosan combined with nisin on Shewanella spp. isolated from Pseudosciaena crocea. Food Control 2017, 79, 349-355.

12. Fei, L.; Hong, Y.L.; Cai, J.H.; Wei, Q.Q.; Zhou, X.; Ding, Y.T.; Liu, Z.F.; Liu, L. Antimicrobial effect and mechanism of cinnamon oil and gamma radiation on Shewanella putrefaciens. J. Food Sci. Technol. 2018, 55, 3353-3361.

13. Zhang, N.; Lan, W.; Wang, Q.; Sun, X.; Xie, J. Antibacterial mechanism of Ginkgo biloba leaf extract when applied to Shewanella putrefaciens and Saprophytic staphylococcus. Aquac. Fish. 2018, 3, 163-169. [CrossRef]

14. Vinai Chittezham, T.; Sadykov, M.R.; Chaudhari, S.S.; Joselyn, J.; Endres, J.L.; Widhelm, T.J.; Jong-Sam, A.; Jawa, R.S.; Zimmerman, M.C.; Bayles, K.W. A central role for carbon-overflow pathways in the modulation of bacterial cell death. PLoS Pathog. 2014, 10, e1004205.

15. Sun, G.; Yang, Q.; Zhang, A.; Guo, J.; Liu, X.; Wang, Y.; Ma, Q. Synergistic effect of the combined bio-fungicides $\varepsilon$-poly-l-lysine and chitooligosaccharide in controlling grey mould (Botrytis cinerea) in tomatoes. Int. J. Food Microbiol. 2018, 276, 46-53. [CrossRef] [PubMed]

16. Lin, L.; Gu, Y.; Li, C.; Vittayapadung, S.; Cui, H. Antibacterial mechanism of $\varepsilon$-Poly-lysine against Listeria monocytogenes and its application on cheese. Food Control 2018, 91, 76-84. [CrossRef]

17. Tang, H.; Chen, W.; Dou, Z.M.; Chen, R.; Hu, Y.; Chen, W.; Chen, H. Antimicrobial effect of black pepper petroleum ether extract for the morphology of Listeria monocytogenes and Salmonella typhimurium. J. Food Sci. Technol. 2017, 54, 2067-2076. [CrossRef]

18. Xu, J.G.; Liu, T.; Hu, Q.P.; Cao, X.M. Chemical Composition, Antibacterial Properties and Mechanism of Action of Essential Oil from Clove Buds against Staphylococcus aureus. Molecules 2016, 21, 1194. [CrossRef]

19. Diao, M.; Qi, D.; Xu, M.; Lu, Z.; Lv, F.; Bie, X.; Zhang, C.; Zhao, H. Antibacterial activity and mechanism of monolauroyl-galactosylglycerol against Bacillus cereus. Food Control 2018, 85, 339-344. [CrossRef]

20. Zhang, Y.; Liu, X.; Wang, Y.; Jiang, P.; Quek, S.Y. Antibacterial activity and mechanism of cinnamon essential oil against Escherichia coli and Staphylococcus aureus. Food Control 2016, 59, 282-289. [CrossRef]

21. Shen, S.; Zhang, T.; Yuan, Y.; Lin, S.; Xu, J.; Ye, H. Effects of cinnamaldehyde on Escherichia coli and Staphylococcus aureus membrane. Food Control 2015, 47, 196-202. [CrossRef]

22. Eom, S.H.; Lee, D.S.; Jung, Y.J.; Park, J.H.; Choi, J.I.; Yim, M.J.; Jeon, J.M.; Kim, H.W.; Son, K.T.; Je, J.Y. The mechanism of antibacterial activity of phlorofucofuroeckol-A against methicillin-resistant Staphylococcus aureus. Appl. Microbiol. Biotechnol. 2014, 98, 9795-9804. [CrossRef] [PubMed]

23. Filomena, N.; Florinda, F.; Laura, D.M.; Raffaele, C.; Vincenzo, D.F. Effect of essential oils on pathogenic bacteria. Pharmaceuticals 2013, 6, 1451-1474.

24. Pei, Q.; Li, Y.; Ge, X.; Tian, P. Multipath effects of berberine on peach Brown rot fungus Monilinia fructicola. Crop Prot. 2019, 116, 92-100. [CrossRef]

25. Huang, Z.; He, K.; Song, Z.; Zeng, G.; Chen, A.; Yuan, L.; Li, H.; Hu, L.; Guo, Z.; Chen, G. Antioxidative response of Phanerochaete chrysosporium against silver nanoparticle-induced toxicity and its potential mechanism. Chemosphere 2018, 211, 573-583. [CrossRef]

26. Yang, S.; Liu, L.; Li, D.; Xia, H.; Su, X.; Peng, L.; Pan, S. Use of active extracts of poplar buds against Penicillium italicum and possible modes of action. Food Chem. 2016, 196, 610-618. [CrossRef]

27. Villegas-Mendoza, J.; Cajal-Medrano, R.; Maske, H. INT (2-(4-Iodophenyl)-3-(4-Nitrophenyl)-5-(Phenyl) Tetrazolium Chloride) Is Toxic to Prokaryote Cells Precluding Its Use with Whole Cells as a Proxy for In Vivo Respiration. Microb. Ecol. 2015, 70, 1004-1011. [CrossRef]

28. Wang, Y.; Zhang, Y.; Shi, Y.-q.; Pan, X.-h.; Lu, Y.-h.; Cao, P. Antibacterial effects of cinnamon (Cinnamomum zeylanicum) bark essential oil on Porphyromonas gingivalis. Microb. Pathog. 2018, 116, 26-32. [CrossRef] 
29. Sun, X.-h.; Zhou, T.-t.; Wei, C.-h.; Lan, W.-q.; Zhao, Y.; Pan, Y.-j.; Wu, V.C.H. Antibacterial effect and mechanism of anthocyanin rich Chinese wild blueberry extract on various foodborne pathogens. Food Control 2018, 94, 155-161. [CrossRef]

Sample Availability: Not available.

(C) 2019 by the authors. Licensee MDPI, Basel, Switzerland. This article is an open access article distributed under the terms and conditions of the Creative Commons Attribution (CC BY) license (http://creativecommons.org/licenses/by/4.0/). 